\title{
Prosthetic hernioplasty in elderly people: personal experience
}

\author{
Fulvio Freda*, Marco Scorzelli, Vincenzo Padovano, Domenico Larotonda, Raffaella Guerniero, Pasquale Petronella \\ From 26th National Congress of the Italian Society of Geriatric Surgery \\ Naples, Italy. 19-22 June 2013
}

\section{Background}

Inguinal hernia is the most prevalent among the hernias that interested the abdominal wall with higher incidence in male than female, moreover it is more frequent in elderly than in younger patients. The incidence rises from 11 per 10,000 person-years aged 16-24 years to 200 per 10,000 person-years aged 65 years and above.

According to the literature the safest approach to geriatric patients is to perform hernioplasty in open surgery using local anaesthesia. The elderly patient has special features, typically related to the general conditions. Local anesthesia and postoperative analgesia are sufficient to solve the problems of old age. Over the last twenty years the surgical treatment of inguinal hernias has undergone significant changes. Today, the use of prothesis is the technique most used.

There are not many differences between the techniques "tension free sutures less" and "tension free sutures no less".

\section{Materials}

From January 2005 to December 2011 at the Department of Gerontology, Geriatrics and Metabolic Diseases at the Second University of Naples, we operated 293 patients for inguinal hernia, whose 92 elderly patients (older than 65 years) underwent surgical prosthetic hernioplasty for simple inguinal hernias. Patients with recurrence, bilateral hernia, large size hernia and all cases that underwent general anaesthesia were excluded from the study.

\footnotetext{
* Correspondence: fulvio.freda@unina2.it

Second University of the Study of Naples, School of Medicine, Department of Gerontology, Geriatry and Metabolic Diseases, U.O. of Geriatric Surgery, Piazza Miraglia, 5 - 80138, Naples, Italy
}

(c) 2013 Freda et al; licensee BioMed Central Ltd. This is an Open Access article distributed under the terms of the Creative Commons Attribution License (http://creativecommons.org/licenses/by/2.0), which permits unrestricted use, distribution, and reproduction in any medium, provided the original work is properly cited.

\section{Results}

In the elderly there are multiple concomitant diseases compared with young, like respiratory or cardiovascular or metabolic diseases, for example.

We reported only 1 recurrence (1.08\% of cases) with the "tension free no suture less" technique. As concerns postsurgical pain, no type of analgesic treatment was required for the most of cases treated.

Thanks to the prothesis and concomitant use of local anaesthetic you get a decrease of hospitalization time for the patients.

The duration of surgical treatment is about $45 \mathrm{~min}$; the most of patients were discharged either one day after or two days after surgery due to severe concomitant pathologies such as ischemic cardiopathy, hypertension, renal insufficiency, obesity, hepatic cirrhosis, moderate-severe $\mathrm{BPCO}$ or decompensated diabetes mellitus.

The "tension free suture less" and "tension free no suture less" techniques also decreases morbidity connected to respiratory (atelectasis, infection) and circulatory complications (deep vein thrombosis, pulmonary embolism). If performed correctly, these techniques, which are based on reinforcing the posterior wall of the inguinal canal through the use of a prosthesis, display a recurrence rate of $0.1-0.3 \%$.

The surgical prosthetic hernioplasty associated with the so-called "nerve sparing" technique - that is to identify and preserve the nerves during surgery - reduce postoperative pain and allow the patients to return soon to them normal physical activity.

\section{Conclusions}

It is our opinion that the best treatment of inguinal hernia in the elderly patients is the surgical prosthetic hernioplasty associated with local anaesthesia. It is to be considered, moreover, that thanks to the use of "nerve sparing" 
technique you have a decrease in postoperative pain treatment.

Elective inguinal hernia repair under local anesthetic has a good outcome also in the elderly even if there are significant comorbidities. So in our opinion hernioplasty under local anesthesia is quite safe and feasible in patients over 65 years.

Published: 16 September 2013

\section{References}

1. Amato B, Compagna R, Della Corte GA, Martino G, Bianco T, Coretti G, Rossi R, Fappiano F, Aprea G, Puzziello A: Feasibility of inguinal hernioplasty under local anaesthesia in elderly patients. BMC Surg 2012, 12(Suppl 1):S12, doi: 10.1186/1471-2482-12-S1-S2.

2. Beltrán MA, Cruces KS: The outcomes of open tension-free hernioplasty in elderly patients. Hernia 2006, 10(5):395-400.

3. Compagna R, Vigliotti G, Coretti G, Amato M, Aprea G, Puzziello A, Militello C, lacono F, Prezioso D, Amato B: Comparative study between Levobupivacaine and Bupivacaine for hernia surgery in the elderly. BMC Surg 2012, 12(Suppl 1):S12, doi: 10.1186/1471-2482-12-S1-S12.

4. Shaikh AR, Rao AM, Muneer A: Inguinal mesh hernioplasty under local anaesthesia. J Pak Med Assoc 2012, 62(6):566-9.

5. Simons MP, Aufenacker T, Bay-Nielsen M, Bouillot JL, Campanelli G, Conze J, de Lange D, Fortelny R, Heikkinen T, Kingsnorth A, Kukleta J, MoralesConde S, Nordin P, Schumpelick V, Smedberg S, Smietanski M, Weber G, Miserez M: European Hernia Society guidelines on the treatment of inguinal hernia in adult patients. Hernia 2009, 13(4):343-403.

\section{Submit your next manuscript to BioMed Central} and take full advantage of:

- Convenient online submission

- Thorough peer review

- No space constraints or color figure charges

- Immediate publication on acceptance

- Inclusion in PubMed, CAS, Scopus and Google Scholar

- Research which is freely available for redistribution

Submit your manuscript at www.biomedcentral.com/submit 